\title{
Moving on Towards a Workable Climate Regime
}

\author{
Jaime de Melo
}

\author{
$C$ Jaime de Melo, Scientific Director at Ferdi, \\ Professor Emeritus at the University of Geneva, CEPR \\ and Geneva Business School.
}

\begin{abstract}
The Paris Agreement (PA) signed by 175 parties is now a Treaty since a quorum of signatories has been obtained. This Treaty is really the first important step taken to limit temperature increase, as pledges, if sustained and far more ambitious beyond 2030, would drastically limit the projected temperature increase from projections in the absence of measures to limit emissions of greenhouse gases. Contributions however fall short of the intentions to limit temperature increase to the $+1.5^{\circ}$ to $+2^{\circ}$ Celsius range since the onset of industrialization. Drawing on recent contributions, this paper reviews where we stand in tackling four challenges ahead: (i) taking fuller cognizance of the accumulating scientific evidence calling for urgent action; (ii) designing an architecture that will render effective the blend of 'bottom-up' and 'top-down' approaches; (iii) choosing policy options and tackling the slow transition to a low-carbon economy, and; (iv) raising finance and addressing burden sharing.
\end{abstract}

JEL codes: O44, F18

I thank Scott Barrett and Carlo Carraro for fruitful collaboration, Jean-Marie Grether, Jie He, Nicole Mathys and participants at the XXVIII Mondragone seminar June 23-4, 2016 for comments and Adrien Corneille and Vincent Nossek for logistic support. I am grateful to the French National Research Agency for its support under program ANR-10-LABX-14-01. Views and errors are mine and do not reflect those of the institutions to which I am affiliated. 



\section{Contents}

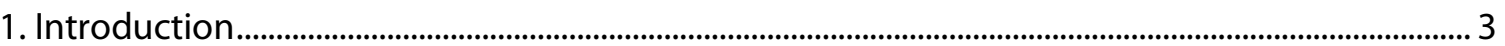

2 Our carbon budget requires immediate action................................................................................. 4

2.1 Emission pathways, uncertainty and the precautionary principle............................................... 6

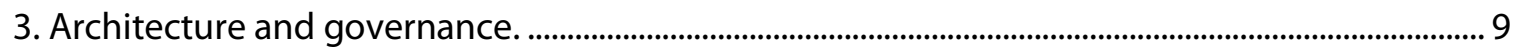

3.1 Comparing Pledges............................................................................................................................. 9

3.2 Experimental Governance and Building Blocs .................................................................................... 11

3.3. Greening the GATT ............................................................................................................................... 11

4. Policy options

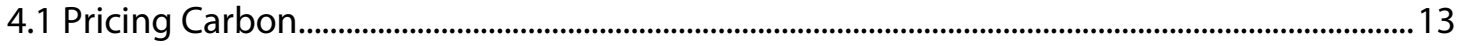

4.2 Technology-based options and the Transition to a low-carbon economy.............................. 14

5. Damage Incidence and Burden sharing.................................................................................................... 15

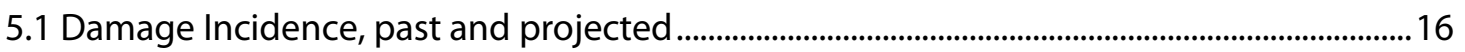

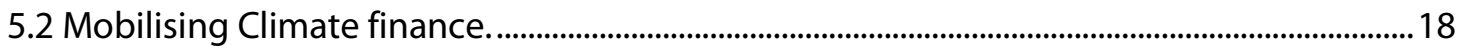

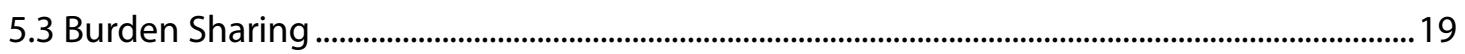

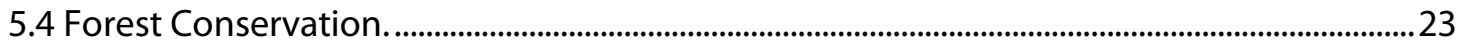

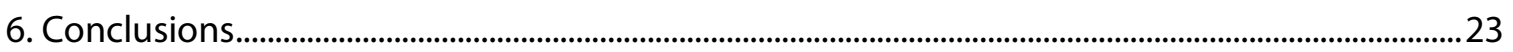

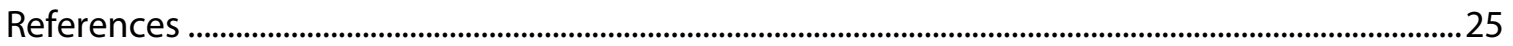

\section{Figures and Tables}

Figure 1: Effect of multiple targets on estimated carbon budget ......................................................... 4

Figure 2 here : Emission Pathways consistent with a $2^{\circ} \mathrm{C}$ target............................................................ 6

Figure 3: Past (3a) and Projected (3b) CO2 emissions by region ......................................................17

Figure 4: Post 2030 emission targets under alternative 'burden sharing' approaches ..................21

Table 1 Ex-ante assessment of NDCs of Selected Countries......................................................................10

Table 2: Burden sharing under a CAT: the EU Climate Directive: 2010-2014......................................20

Table 3 Contributions to a Climate Adaptation Fund .................................................................................22 
"We Knew the Basic Principles on which to build: Cost-effectiveness, equity, joint implementation, and comprehensiveness, but not how to make them operational"

Gro Harlem Bruntland (recollection of Rio 1992 conference during Kyoto Protocol Negotiations quoted in Schmalensee (1998))

"We basically have three choices: mitigation, adaptation and suffering. We're going to do some of each. The question is what the mix is going to be. The more mitigation we do, the less adaptation will be required and the less suffering there will be."

John Holdren, Director of Office of Science and Technology Policy, US

\section{Introduction}

Following the ratification of major contributors to CO2 emissions in 2016, the Paris Agreement (PA), successor to the Kyoto Protocol (KP) will come into effect at its expiration in 2020 as ratification by a quorum of signatories has been obtained by the end of 2016. The PA will be a Treaty. Compared with the KP that only covered $14 \%$ of global Green House Gas (GHG) emissions, with signatories accounting for $96 \%$ of GHG emissions, the PA has been hailed as a huge diplomatic success. The PA will have a review process starting in 2023--repeated on a 5-year cycle-- that will assess contributions to mitigation, adaptation and finance in the light of future scientific results from the IPCC. This new architecture blends the "bottom up" (Nationally Determined Contributions (NDCs)) and "top down" elements for rules on Monitoring, Reporting and Verification (MRV). A move forward towards climate finance for adaptation and mitigation in developing countries also represents an important step in the right direction. In a nutshell, the PA is the first occasion where all nations have agreed to contribute, albeit on a voluntary non-binding basis, to mitigate climate change by reducing their $\mathrm{CO} 2$ emissions. One can say with some confidence that we have moved beyond the situation described by Bruntland during the KP negotiations in the introductory quote above. Comprehensiveness has been achieved and we have taken some steps to address effectiveness but many challenges remain in building and sustaining a workable and effective climate regime. Simply put, as pointed out by Holdren, we have not yet faced up to deciding about the mix between adapting, mitigating and suffering which is necessary for a workable climate regime. Drawing on recent contributions, I review where we stand on four challenges: (i) taking fuller cognizance of the accumulating scientific evidence calling for urgent action (section 2); (ii) designing an architecture that will render effective the blend of 'bottom-up' and 'top-down' approaches (section 3); (iii) policy options and facing up to a slow transition towards a low-carbon economy (section 4), and; (iv) reaching an acceptable burden sharing between rich and poor nations (section 5). 


\section{Our carbon budget requires immediate action}

The most recent IPCC report of 2014(AR5) concludes that 'warming in the climate system is unequivocal', that 'human influence on the climate system is clear' and that these changes will have a profound influence on land, food and water, the primary resources for human subsistence. Negotiations at the PA have concentrated on the objective of controlling the increase in the average surface temperature. Figure 1 is an estimated budget for fossil-fuel emissions to meet the PA objective of $+2^{\circ} \mathrm{C}$. It is derived under the assumption that the near-linear relationship between global mean surface warming and the stock of $\mathrm{CO} 2$ in the atmosphere since industrialization will continue to hold until the end of the century (IPCC AR5 report). The range in figure 1 reflects the believed uncertainty about the climate sensitivity " $\mathrm{S}$ "(more on the uncertainty of $\mathrm{S}$ below) that defines the equilibrium surface warming from a doubling of atmospheric $\mathrm{CO} 2$ concentrations in the range that would lead to a moderate increase in temperature, i.e. in the range of $1.5^{\circ} \mathrm{C}-3.0^{\circ} \mathrm{C}$. . Of our budget of approximately 1000 billion tons (Gt) from 1750 to 2100 of which 545Gt had been emitted by 2014,leaves 455 billion tons to be emitted in the future or 245GT if the effects of additional greenhouse gases (methane, nitrous oxide, HFCs) are taken into account. Thus at the current rate of emissions, we have about 25 years of emissions under the narrow objective of meeting the $2^{\circ} \mathrm{C}$ target (Stocker 2015).

\section{Figure 1: Effect of multiple targets on estimated carbon budget}

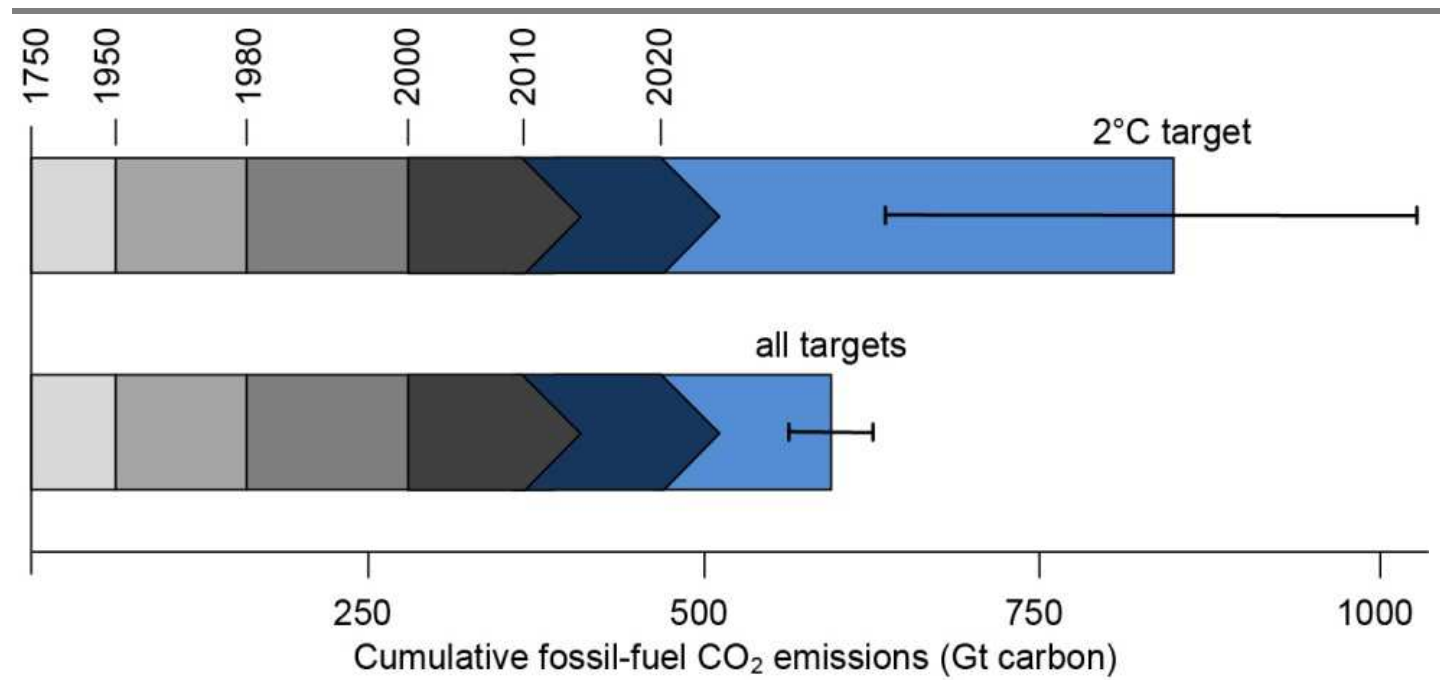

Source: Stocker (2015, figure 4)

\footnotetext{
${ }^{1}$ It is believed that the near linear relation between warming and the stock of $\mathrm{CO} 2$ is likely to hold for warming of up to $+3^{\circ}$ and that we do not know enough to model the $\mathrm{CO} 2$-temperature relation for warming beyond that range. We know nothing about 'extreme warming', usually understood to be an increase in temperature of $+4.5^{\circ}$ since the beginning of industrialization because the probabilities of temperature changes are unknown (Knigthian uncertainty). Wagner and Zeckhauser (2016) review and discuss the state of knowledge about the links between CO2 concentrations and temperature.
} 
But climate change has other effects beyond increases in atmospheric temperatures. Climate change is affecting all components of the Earth system resulting in increases in the occurrence and strength of extreme events like heat waves and a melting of ice sheets and glaciers. Close to 90 percent of GHGs trapped in the atmosphere are absorbed by the sea and the increase in atmospheric $\mathrm{CO} 2$ emissions is acidifying the entire world ocean. These changes are affecting the primary resources for human subsistence: land, food and water. In recognition of the associated dangers for the sustainability of the planet, article 2 of the UNFCCC calls for stabilizing concentrations of GHGs in the atmosphere. The estimates in the bottom of figure 1 take these sustainability objectives of Article 2 into account. This lowers our remaining carbon budget for the century by 30 percent leaving about 17 years before reaching zero net GHG emissions.

Urbanization will continue, particularly in the high-population growth low-income countries. This will further reduce our carbon budget, though by how much depends on what we do to "green our cities" especially those that are not yet built. Currently, cities account for over $70 \%$ of global GHG emissions while they host $54 \%$ of world population, reflecting that per capita emissions in rural areas is about a third of per capita emissions in urban areas. Cities are projected to account for $90 \%$ of the projected population increase by mid-century. This urbanization will take place overwhelmingly in developing countries where vulnerability to climate impacts are highest (vulnerability is highest in low-income countries because the physical assets of the poor like housing are usually in areas exposed to natural disasters because these are the only areas the poor can afford). It is also likely that climate change reducing the necessary moisture for agriculture in the low-latitude zones in Africa will accelerate migration towards cities. ${ }^{2}$

From a climate perspective, urban growth has two components: a stock component from building infrastructure and a flow component from urban living habits. Applying the average carbon replacement value for key construction materials of Annex I countries of $50 \mathrm{tCO}$ eq/capita will take one third of the total carbon budget for the 21 st century for a $+2^{\circ} \mathrm{C}$ temperature rise (Bigio (2015)). This would exceed the 40 percent already emitted during the 2000-11 period and if urban sprawl would economize on the stock component of urban-related emissions (less cement, steel and aluminum all heavy $\mathrm{CO} 2$ emitters), this would be compensated by a larger emission flow associated with longer commuting times. As an example, at 400 tons per capita, the carbon footprint of Atlanta is about 10 times that of Barcelona, a city of similar size (World Bank ,2009). In developing countries where urbanization is ongoing, a combination of urban adaptation to climate change and mitigation by locking in to energy-efficient infrastructure will require external financial resources. Raising the necessary funds and using these funds effectively is a big challenge ahead as most urban growth momentum is expected to occur in small to medium size cities in poor countries where governance and institutional capacities are usually weakest. ${ }^{3}$

\footnotetext{
${ }^{2}$ Drawing on a large panel of over 1000 cities covering 29 African countries, Henderson et al. (2017) study the effects of climate variability on city income growth (proxied by night lights) over the period 1992-2008. They show that decreased moisture increases city population size and incomes but only towards cities with more industrialized areas.

${ }^{3}$ Mo (2016) estimates that China will need over $\$ 1$ trillion in the next 5 years to finance energy-efficient buildings, low carbon transport and clean energy in its cities and that the government can only afford up to 15 percent of that amount.
} 


\subsection{Emission pathways, uncertainty and the precautionary principle.}

Since the goal of stabilizing greenhouse gases was agreed in 1994, by procrastinating we have already consumed $42 \%$ of the then remaining budget. Starting now rather than in 2020 when the PA comes into effect is urgent since over a given time horizon, the effort at reducing emissions will have to be greater because the stock of $\mathrm{CO} 2$ (and hence the realized temperature increase) will be greater. ${ }^{4}$ Figure 2 shows the costs of procrastination by showing estimates of three pathways to reach zero net emissions that would be compatible with the $+2^{\circ} \mathrm{C}$ relative to the pre-industrial level by the end of the century under the relatively robust assumption that maximum warming relative to pre-industrial times caused by $\mathrm{CO} 2$ emissions is near proportional to the stock of $\mathrm{CO} 2$ emission up to $+3^{\circ} \mathrm{C}$. The simulations assume that there will be no active removal of carbon from the atmosphere. Starting in 2015 would have required a pathway with emissions falling at the rate of $4.4 \%$ a year, but the rate climbs to $6.3 \%$, if the decline starts in 2020 when the PA comes into effect. And if we were to procrastinate further, an (unreachable short of geo-engineering) $25.5 \%$ annual would be required if the decline were to start in 2030.

\section{Figure 2 here : Emission Pathways consistent with a $2^{\circ} \mathrm{C}$ target}

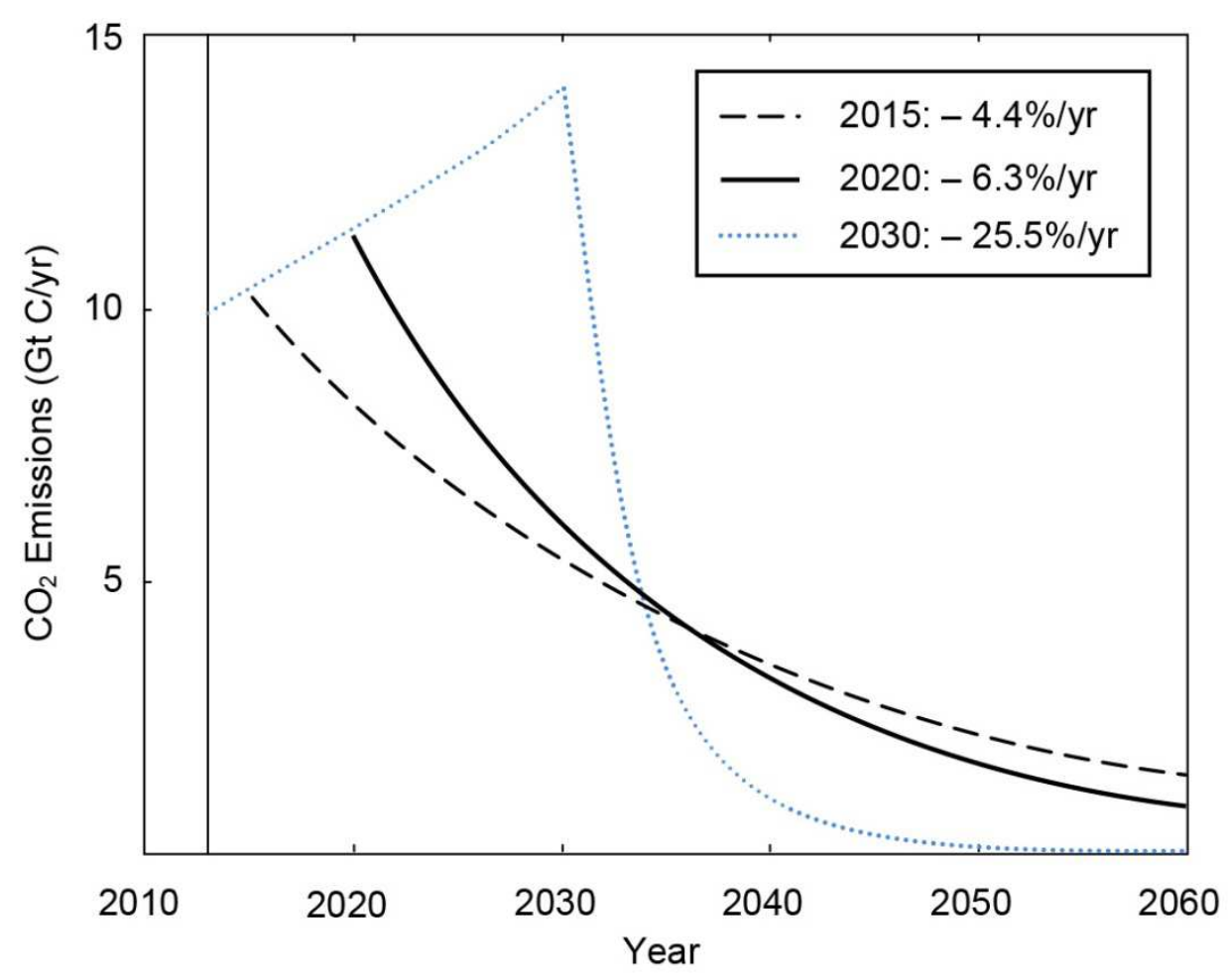

Source : Stocker (2015, figure 5)

\footnotetext{
${ }^{4}$ The recently concluded HFC amendment (October 2016) to the Montreal Protocol took seven years of negotiations. In the meantime, HFC gases have been growing at 10-15\% per year and the amendment will only kick in for developing countries in 2024 or 2028 who will start cuts in 2029 or 2032 . Hope must be placed that the 'tipping point' characteristic of this amendment will lead to a rapid shift towards less damaging substances by the industry leaders following the 'start and strengthen' characteristic of the Montreal Treaty.
} 
If our current understanding of the science of climate change suggests that the pathways in figure 2 may be plausible, there is uncertainty about climate change, about damages from climate change and about the interaction between the two. ${ }^{5}$ This means uncertainty about the estimated damages and about how these damages are captured in the climate models and in the Integrated Assessment Models (IAMs) that translate these changes into damages for humans. Burke et al. (2015) evaluate these two kinds of uncertainty. Rather than relying on one or two climate models (usually the Hadley Centre Climate model), they submit econometric estimates of outcomes (productivity changes, civil war, GDP growth to changes in temperature) to each one of 7 respected global climate models under the same growth projection scenario. ${ }^{6}$ They quantify the role of climate uncertainty as reflected in the climate models relative to regression uncertainty about the effects of temperature extremes on outcomes. They find that climate uncertainty is relatively more important for studies of US agriculture and regression uncertainty for African studies. Their Monte Carlo results show that failing to account for climate uncertainty severely underestimates the thickness of the tails of the distribution of future outcomes. For four out of the seven studies, a worst-case outcome is understated by at least a factor of 2 (Burke et al. p. 470).

There is uncertainty about the temperature- $\mathrm{CO} 2$ link used in the equations describing the relation between temperature and the stock of $\mathrm{CO} 2$ in the IAMs. These are captured by the 'climate sensitivity' (S) mentioned above. As noted by Schelling (2007) "for a quarter century, the range of uncertainty [about S] has been a factor of three". A lower heat capacity implies 'front-loading', i.e. earlier warming for a given total warming. Front loading warming increases the value of mitigation policy.

Uncertainty about sea level rise caused by an increase in temperature is another case of physical uncertainty. Until recently, climate models have been unable to replicate the estimated large sea level swings reconstructed from geological data during the Pliocene and the Last Interglacial (LIG) period (about 100,000 years ago) when the concentrations were about the same as now, temperatures were $0-2^{\circ} \mathrm{C}$. higher and the sea level was 6-9 meters higher. Such increases required disappearance of the Greenland ice sheet and the collapse of the antarctic ice sheet calling for a modelling of the mechanical collapse of ice cliffs where marine terminating ice margins approach 1 $\mathrm{km}$. with vertical exposure above $90 \mathrm{~m}$. Recent modelling by De Conto and Pollard (2016) has successfully calibrated these sea level rises in the distant (Pliocene) and more recent (LIG) periods. These new estimates project an increase in sea level above $1 \mathrm{~m}$. by the end of the century. These estimates also predict that even with extraordinary success at cutting emissions, the West

\footnotetext{
${ }^{5}$ Stern (2013) reports that it is likely that an increase of $+3^{\circ} \mathrm{C}$ that might occur when concentrations would rise from the current $400 \mathrm{pm}$ to $750 \mathrm{ppm}$ has not been experienced for around 3 million years so for the practical purpose of modelling the effects of climate change on human we are already in uncharted territory. Stocker $(2015$, figure 4) displays the key climate change-related risks whose levels increase with rising temperatures that are linked to annual GHG emissions. Stern also lists the effects that might emerge strongly at $+3^{\circ} \mathrm{C}$.

${ }^{6}$ The IPCC developed a Special Report on Emissions Scenarios (SRES). Burke et al. pick a balanced scenario from the SRES to apply the econometric estimates of the effects of changes in temperature and precipitation on outcomes (e.g. agricultural productivity) that they feed to each global climate model to derive a range of estimates of impacts on agriculture, economic growth, and probability of conflict.
} 
Antarctica ice sheet cannot be saved, leading to a locking of the sea-level rise of more than 5 meters.

There is also uncertainty about the damages of a given increase in temperature. In the standard formulation of the damage function in the widely used DICE model, the calibration gives only a $17 \%[50 \%]$ consumption loss from an increase in temperature of $\mathrm{T}=+10^{\circ} \mathrm{C}\left[\mathrm{T}=+20^{\circ} \mathrm{C}\right]$ above the preindustrial level. Evidence of damages to agricultural productivity, health and increased conflict from past extremes in temperature is accumulating. These estimates suggest large damages for the temperatures we are likely to experience this century. ${ }^{7}$ Calibrating the damage function in the DICE model to result in a loss of output of $50 \%$ if $\mathrm{T}=+4^{\circ} \mathrm{C}$-- temperatures that have not been seen in 10 million years -- Dietz and Stern (2015) show that business-as-usual trajectories of GHG produce large negative impacts on growth. Under these assumed damage estimates, optimal carbon taxes would grow from a $\$ 30-100 / \mathrm{tCO} 2$ range in 2015 to a $\$ 80-260 / \mathrm{tCO} 2$ range within two decades.

The evidence above tell us that our close to business-as-usual path of emissions is threatening us and that the pledges under the PA so far could be characterized as being more reactionary than precautionary. In the situation where the intensity of potential damage is dynamic (i.e. it depends on the stock of (O2), the probability of damage is revised upwards through time, and catastrophe is a possibility, then, the conditions for an immediate action are met and precautionary action is warranted (Gollier et al. (2010).

\footnotetext{
7 In the (IAMs), the S parameter measures the system's capacity to absorb heat and return to a steady state where our planet's net energy content remains constant. The probability of drawing a large value for $\mathrm{S}$ occurs when the upper tail of the distribution approaches zero more slowly than the exponential distribution. (i.e. has a 'tail'). Extreme warming depends also on 'effective heat capacity' (the amount of energy required to increase the earth's temperature by $+1^{\circ} \mathrm{C}$ ), i.e. the rate at which heat is taken up by the oceans. Calel et al. (2014) explore the sensitivity of the DICE model (Nordhaus (2008)) results to a lower heat capacity and larger $S$ values. They also explore the possibility of larger probability damages with a log-normal pdf with the same density in the tail (i.e. the same probability of 0.25 density in the tail for temperature above $4.5^{\circ}$ ). They show that the discounted consumption gains from taking these factors into account for a $500 \mathrm{ppm}$ policy in the DICE model only have marginal effects on the gains from mitigation which amounts to precluding a catastrophic scenario. The conclusion is that large gains from mitigation policies occur from adding convexity to the standard quadratic Nordhaus damage function as in Dietz and Stern (2015).
} 


\section{Architecture and governance.}

Our 'prisoners' dilemma' calls for cooperation-building actions on several fronts. Achieving this cooperation involves mobilizing stakeholders beyond central governments to include the private sector and civil society at large. In turn, cooperation depends on trust which requires that 'comparable countries' undertake 'comparable mitigation efforts'. How much can we expect from strategies that aim at increasing cooperation and effort ('experimental governance' and 'building blocs' strategies)? How should one 'green the GATT' to help avoid a clash of the trade and climate communities by tackling 'trade leakage' and free-riding.

\subsection{Comparing Pledges}

Acknowledging that making emission limits pledged by countries legally binding is not yet feasible, the talk before Paris was to make provisions for Monitoring, Reporting, and Verification (MRV) legally binding. In great part, this is because it is essential to know whether countries' actual behavior is tracking their pledges. As argued by Aldy (2014), greater accountability can cause behavioral change: states may be more likely to meet their pledges if their actions can be observed. Indeed, MRV should extend beyond emission levels and related outputs, to include policies and measures for reducing emissions, investment in technology $R \& D$, financing, adaptation, and geoengineering. Strong procedural obligations of reporting were adopted in the PA, although in the end countries are only required to 'pursue domestic mitigation measures, with the aim of achieving the objectives of [their] NDCs' which, as noted by Bodansky (2016), is not a legal obligation.

Under these circumstances, transparency and comparability is essential to demonstrate effort to ensure net benefits and encourage participation. Are similar countries making similar pledges? Are countries pledging to contribute their fair share? This is a difficult question to answer because the NDCs are expressed in different ways (in terms of a base year, a forecast, emissions intensity, peaking year, renewable energy goals) and no single metric that satisfies the three criteria of comprehensiveness, measurability and replicability, exists. Recognizing these trade-offs, Aldy et al. (2016) use model-based simulations to report estimates of emissions, carbon prices and cost metrics obtained from translating pledges into a similar format then estimating the net costs of meeting these pledges in a cost-minimizing way over the period 2020-2030. Table 1 from their paper shows a selection of results for five major polluters from four models, each having a different representation of the energy sector. 
Table 1: Ex-ante assessment of NDCs of Selected Countries

\begin{tabular}{|c|c|c|c|c|c|c|c|c|}
\hline & & Avera & je annua & I GHG emissi & ons & & & \\
\hline & & & 2025 & -2030 & & change (\%) & $\begin{array}{c}\text { (US\$ per } \\
\left.\mathrm{tCO}_{2} \mathrm{e}\right)\end{array}$ & (\% GDP) \\
\hline & & $\begin{array}{c}\text { Level } \\
\left(\mathrm{MtCO}_{2} \mathrm{e}\right) \\
(1)\end{array}$ & $\begin{array}{c}\text { versus } \\
1990 \\
(2)\end{array}$ & $\begin{array}{c}\text { versus } 2005 \\
\text { (3) }\end{array}$ & $\begin{array}{l}\text { versus } \\
\text { BAU } \\
\text { (4) }\end{array}$ & $\begin{array}{c}2015-2030 \\
(5)\end{array}$ & (6) & $(7)$ \\
\hline US & DNE21+ & 5,091 & -18 & -30 & -35 & $-4,0$ & 109 & 0,42 \\
\hline & WITCH & 5,140 & -5 & -26 & -35 & $-4,3$ & 101 & 0,76 \\
\hline & GCAM & 4,358 & -29 & -34 & -41 & $-4,8$ & 100 & 0,84 \\
\hline & MERGE & 5,407 & -7 & -22 & -21 & $-3,7$ & 40 & 0,28 \\
\hline EU & DNE21+ & 3,733 & -35 & -30 & -32 & $-3,3$ & 177 & 0,59 \\
\hline & WITCH & 3,720 & -32 & -30 & -32 & $-4,4$ & 116 & 0,51 \\
\hline & GCAM & 3,500 & -38 & -32 & -33 & $-3,8$ & 100 & 0,57 \\
\hline & MERGE & 3,836 & -30 & -25 & -25 & $-3,0$ & 45 & 0,31 \\
\hline China & DNE21+ & 17,353 & 338 & 109 & -4 & $-4,3$ & 1 & $-0,20$ \\
\hline & WITCH & 16,526 & 413 & 91 & -20 & $-4,0$ & 33 & 1,60 \\
\hline & GCAM & 13,809 & 149 & 49 & -8 & $-4,1$ & 12 & 0,04 \\
\hline & MERGE & 13,086 & 250 & 77 & -10 & $-3,7$ & 23 & 0,72 \\
\hline India & DNE21+ & 6,366 & 389 & 206 & 0 & $-1,8$ & 0 & 0,00 \\
\hline & WITCH & 4,577 & 278 & 115 & -1 & $-2,6$ & 0 & 0,59 \\
\hline & GCAM & 5,007 & 220 & 121 & -12 & $-2,6$ & 19 & 0,13 \\
\hline & MERGE & 4,787 & 308 & 135 & -2 & $-2,5$ & 0 & 0,22 \\
\hline Japan & DNE21+ & 1,107 & -13 & -21 & -20 & $-3,5$ & 283 & 2,11 \\
\hline & GCAM & 1,139 & -12 & -21 & -17 & $-2,2$ & 91 & 0,01 \\
\hline & MERGE & 1,037 & -12 & -23 & -20 & $-2,2$ & 43 & 0,64 \\
\hline
\end{tabular}

Source: Aldy et al. 2016 table 1

Notes: The left column refers to the model used in the projections. Column 1 is the BAU projections for 2030 (in aggregate quite close to the 60GtCO2e predicted by IPCC WGIII). Columns 2,3,4 and 5 are predicted emissions. Column 6 is the carbon tax to achieve its pledge cost-effectively (the marginal abatement cost). For comparison, the mean SCC of carbon for 2030 in the US used for regulatory analysis is $\$ 201557$ per tCO2 in 2030. Column 7 is abatement costs as a share of GDP.

Comparing results reveals several patterns. First, wealthier countries have pledged to make a greater mitigation effort. Second, the very different values for the Social Cost of Carbon (SCC) across countries in column 5 suggest significant economic gains from international emissions trading (cap-and-trade (CAT) schemes)) or carbon tax coordination with the bulk of abatement taking place in the low-income countries (e.g. India) that would receive financial resources from purchases by developed countries as under the Clean Development Mechanism during the KP. Third, the estimates for Japan, a country with low emissions and fewer mitigation options compared with other countries show large cost discrepancies in cost estimates across models (column 7) for similar emission reduction estimates (column 3). Fourth the carbon metrics suggest comparable price increases for the EU, US and Japan and some metrics favor certain countries (e.g. measuring emissions versus 1990 is unfavorable for China and India). Finally, the models only 
estimate mitigation costs; they do not account for benefits from improvements in local air quality co-benefits. ${ }^{8}$

\subsection{Experimental Governance and Building Blocs}

The KP failed to address climate change in a top-down way. The PA tries to build cooperation from the bottom up. With credible MRV, the PA should help governments and other critical players determine what is feasible through coordination and it could establish some momentum in negotiations, so that countries not making serious efforts could be embarrassed as laggards. In this spirit, Keohane and Victor (2015) envisage a three-pronged strategy: first, that goals are to be related to actions; second, that participants that fail to act face significant costs; and, third, that connections be made between various national pledges and the overall goal. In this spirit, States and other actors, including firms, NGOs, international organizations, and subnational authorities, can pursue a "building block strategy" that relies on clubs, institutional linkages, and dominant market actors. ${ }^{9}$ To this, one should add that much impetus should come from 'private authority'. Examples are initiatives by large firms such as Walmart that has pledged to reach a zero net carbon footprint or the initiatives by major cities (the ' $C 40$ ' initiative). ${ }^{10}$ More recently, the setting up of a voluntary standard for disclosure by those companies that produce or emit carbon and how they plan their transition to a net-zero $\mathrm{CO} 2$ emissions world is another example of private authority (Task Force on Climate-Related Financial Disclosures (2016)). These efforts by the private sector would not undermine, but complement the UNFCCC approach it by pursuing related approaches.

\subsection{Greening the GATT}

Along with burden sharing, getting countries to face significant costs if they fall short on cooperation is the most difficult part of the PA. An open trading system will be key to implement the PA. First, technology development and transfer is necessary to insure the availability of lowcarbon technologies for all countries. So far, because of politics and limited resources, the Technological Mechanism (TM) convention established as part of the Cancun Agreements, has met with mixed success. ${ }^{11}$ The TM has not yet moved forward towards igniting the hoped-for

\footnotetext{
${ }^{8}$ Estimating own benefits for the top $20 \mathrm{CO} 2$ emitters from reducing reducing missions, Parry, Veung and Heine (2014) estimate co-benefits amounting to a reduction of global $\mathrm{CO} 2$ emissions by $20 \%$.

${ }^{9}$ Stewart, Rudyk and Oppenheimer (2015) give examples. Multilateral banks could agree not to finance new coal-fired electricity generation projects; industry groups setting standards for wind turbines that confer upon them a competitive advantage; and the sharing of technical information on opportunities to reduce emissions.

${ }^{10}$ See Jessica Green (2013) for a causal theory of private authority where a demand for private authority will arise if there are actors that benefit from such rules (reduction in transaction costs, greater credibility, first-mover advantage and improved reputation through 'branding'). Green is aware that entrepreneurial authority is not a substitute for, but can be a complement to, public regulation, citing the case of the International Tropical Timber Agreement (ITTA). When the ITTA was largely failing, an NGO movement around tropical deforestation eventually coalesced into entrepreneurial authority that benefitted firms in ways that public authority could not. Another example is the Montreal Carbon Pledge launched in 2014 by which investors commit to measuring and publicly disclosing the carbon footprint of their investments on an annual basis. With the Carbon Asset Risk initiative, a private-sector led carbon divestment movement is starting.

${ }^{11}$ The TM requires developed countries to assist in technology transfer. As pointed out by Coninck and Bhasin (2015), without discussion on loss and damage, the Technology Mechanism, the Green Climate Fund and the Adaptation Fund,
} 
technological cooperation. This is difficult to achieve as technology transfer goes well beyond the already difficult task of gathering the momentum to kick start a sufficiently sizeable R\&D program recognized by Toman (2015). ${ }^{12} \mathrm{~A}$ trading system in which open licensing mechanism (e.g. 'patent pools', open access, patent information data bases) operate smoothly would help kick-start the needed capacity building in developing countries. Second, an open trading system will be required to stimulate the use of 'environmentally friendly' goods, an objective of the ongoing negotiations on a plurilateral Environmental Goods Agreement (EGA) that are expected to lead to the elimination of trade restrictions for goods on an environmental list. ${ }^{13}$ Third, even though the PA has recognized the principle of linkage through an explicit statement in Article 6.2, cap-and-trade through the linkage of regional, national and sub-national mitigation policies across jurisdictions will also require a well-functioning trading system. Last but not least, because countries are not taking a coordinated approach to carbon pricing, carbon leakage will occur creating tensions in trade as domestic pressures and rent-seeking activities will build to seek protection from carbon embodied in trade flows (Mathys and Melo (2011)). As noted by Fischer (2015), to be effective, antileakage measures will require a multilateral approach.

Mavroidis and Melo (2015) argue that these challenges require a reform of the World Trade Organization (WTO). Up until now the trade and climate regimes have evolved separately. As a result, interpretations of the trade rules reflected in previous WTO decisions constrain the ability of countries, alone or in groups, to develop climate change-friendly policies such as labeling of an energy-efficient technology, efforts to limit fossil fuel subsidies and a re-instatement of Article 31 of the Agreement on Subsidies and Countervailing Measures that classified environmental subsidies as 'non-actionable' for a five year period under the WTO until January 2000. They conclude that the current 'negative' contract in which members can choose environmental policies of their choice needs to be transformed into a 'positive' contract in which WTO membership will require a delegation of national authority to the WTO. The WTO needs to be actively involved in ensuring that trade rules serve the purpose of reducing emissions and not just liberalizing trade. As an example, they discuss how Nordhaus's (2015) recent proposal for a climate club relying on tariffs to punish free-riding would face legal obstacles under the current WTO rules, but that there are alternative ways to stimulate emission reductions by a subset of the WTO membership-a "coalition of the willing" seeking to limit emissions. In short, because of the large gains that a wellfunctioning trading system provides for all WTO members, agreement on a set of rules involving trade restrictions for members not pursuing climate-change averting policies is a promising way to impose costs on those that fall short on effort.

\footnotetext{
developing countries would not have accepted to breakdown the firewall between Annex I and non-Annex I countries as agreed in Durban in 2011. In short, developing countries would not have committed to all countries submitting NDCs.

${ }^{12}$ Among others, beyond funding and recognition of its importance, a research and development cooperation body needs to be instituted within the Technology Mechanism. In sum, as Coninck and Bhasin (2015) put it, 'technology=hardware + software + orgware' where orgware stands for institutional policy and policy capabilities.

${ }^{13}$ So far, progress on the EGA negotiations has been slow. Expected gains from a successful EGA are small as most participants have zero tariffs for most Environmental Goods and negotiations for reductions in barriers to trade in Environmental Services are excluded. See Melo and Vijil (2015).
} 


\section{Policy options.}

Stabilizing GHG concentrations requires progressively reducing emissions to zero, and/or offsetting positive emissions with an equivalent removal of $\mathrm{CO} 2$ directly from the atmosphere. These are the only possibilities. Emissions can be reduced through energy conservation and the substitution of nuclear power for fossil fuels but, because these approaches are limited, attention has focussed on renewable energy (solar and wind). These will need to be scaled up to a much higher level. In addition, $\mathrm{CO} 2$ will need to be removed from the atmosphere. Carbon capture and storage (CCS) is another option with high advantages like reducing leakage-related issues, but it faces high economic and social costs of storage. Hurdles are also faced by solar and carbon geo-engineering, and the latter which is very cheap faces governance problems and does not limit acidification of oceans. And energy transitions from the conventional high-energy emissions (HGE) coal power plants to low GHG emission (LGE) power plants production are intrinsically slow.

\subsection{Pricing Carbon}

How to put a price on carbon remains a baffling question and one is reminded of Bruntland's recollection of the outcome of the Rio 1992 conference in the introductory quote. Efficacy calls for a price path of $\mathrm{CO} 2$ emissions that is not too different across countries and that is relatively credible over the medium to long term to reduce uncertainty for the long-term investment decisions in the construction and transport sectors, both large emitters of CO2. Aiming for convergence towards a single price so as to discourage lobbying activities to get exceptions is essential, but so far it has been slow. If governments had a good estimate of the price of carbon 20 to 30 years down the road, they could issue debt tied to the price of carbon by promising to purchase emission permits if their price fell below a floor.

The regulatory approach based on law and engineering is one avenue. Here, economics enters by the back door while giving leeway for implementation, as in the US Clean Power Plan (CPP). The structure of the CPP is noteworthy because the process it inaugurates--in which implementation flexibility is strong-- mirrors the one that is taking place under the PA. The flexibility in the CPP gives the regulated entities (the U.S. states) the tools to negotiate a cost effective outcome and empowers and reinforces the actions of first movers and bottom-up leadership. In many ways, the CPP is an example of the 'bottom-up' approach adopted at the PA. ${ }^{14}$

The other avenue is a 'straight' economic approach relying on carbon pricing. As of 2015, carbon taxes are applied in 40 national and 20 sub-national jurisdictions engaged in taxing carbon or are involved in Cap And Trade (CAT) schemes. This represents close to a quarter of GHG emissions covering $12 \%$ of annual global emissions for an average price of carbon of $\$ 7 \mathrm{t} / \mathrm{CO} 2$. As an estimate

\footnotetext{
${ }^{14}$ Burtraw (2015) concludes that the failed Copenhagen (2009) pledge to reduce emissions by $17 \%$ from 2005 level by 2020 will be met under the CPP in spite of $30 \%$ growth in real terms with $3-4$ percentage points coming from the expanded supply of natural gas and its substitution for coal and 2-3 percentage points for measures taken by state and local governments.
} 
of the gap between this price and estimates of the Social Cost of Carbon (SCC) from IAMs, using the Nordhaus DICE model (Nordhaus (2008)), Dietz and Stern (2015) estimate that currently, a world average price of carbon should be in the $\$ 30-\$ 100 \mathrm{t} / \mathrm{CO} 2$ range. All the evidence -primo loco in Sweden which has a carbon price over $\$ 100 \mathrm{t} / \mathrm{CO} 2$ and carbon intensity of GDP a third of the world average-is that a carbon tax, when applied at a sufficiently high rate as in Sweden, along with complementary measures, is very effective at reducing emissions and encouraging the development of substitutes for fossil fuels. ${ }^{15}$ It remains that, at the national level, taxes are unpopular so politicians, helped by strong lobbying activity by the fossil fuel industry deny and procrastinate. And at the international level, burden-sharing and fairness also account for the lack of progress in taxing carbon.

A "redirection" of future investments towards low carbon options will be needed. Around US\$90 trillion will need to be invested in infrastructure in the world's urban, land use and energy systems in the next two decades. This amounts to about 5-6 trillion a year. About 1.6 trillion will need to be invested every year in energy supply, half to meet energy demand, half to replace existing plants. How these investments are managed will shape future patterns of growth, productivity and living standards. It is therefore necessary to redirect these investments towards low carbon technological and organizational solutions.

To scale these magnitudes, the additional investments to cope with the societal transformations required to achieve the $2^{\circ} \mathrm{C}$ target are estimated at about 0.6 trillion a year from now to 2030, namely $0.75 \%$ of world GDP in 2013 . By contrast, a $2^{\circ} \mathrm{C}$ consistent carbon tax would generate up to 1.3 trillion USD per year of revenues in OECD economies in 2030. This is equivalent to $2.1 \%$ of OECD aggregate GDP in 2013. Non-OECD countries may need (median estimate) about 50 billion USD in power generation capacity per year until 2030. These estimates reported by Massetti (2015) suggest that, provided an adequate carbon pricing is introduced, financial resources may be sufficient to address the climate change problem. However, the macroeconomic dimension is just one facet of the problem. As always when changes call for significant income redistribution relative to gains (here it is losses), implementation remains the big issue.

\subsection{Technology-based options and the transition to a low-carbon economy}

Technology-based options, themselves dependent on the path of the price of carbon, will be just as important as pricing carbon. New technologies will be needed to close the gap between the cost of fossil fuels and alternative energy sources as the scale of effort increases over time (the costs of large scale solar photovoltaic (PV) are increased by its intermittency and the challenges of

\footnotetext{
${ }^{15}$ The advantages of a tax are well-known: (1) the transparency of the price system reaches billions of peoples that do not have to worry about their taking climate-friendly decisions; (2) it goes a long way towards re-establishing ParetoOptimality; (3) More easily verifiable than other approaches; (4) if the tax is the same across countries, or if there is an agreement on convergence the leakage problem is quasi-solved; (5) the thorny issue of burden-sharing is greatly reduced; (6) because of the nature of the underlying uncertainty, the welfare benefits from the price system are greater than those associated with a quantity system; (7) moving towards a uniform carbon tax would reduce the incentives and possibilities for lobbying activity.
} 
coordinating such dispersed resources with the power grid). In addition, $\mathrm{CO}_{2}$ will need to be removed from the atmosphere. One such option involves using biomass, a renewable form of energy, to produce electricity, and then capturing and storing the carbon (CCS) released in the process of combustion. ${ }^{16}$ However, the problem here is scale. Standard policy approaches such as adoption of a carbon tax will help close the gap between the lower 'energy density' of wind and solar per unit of capital expenditure relative to conventional technologies and also of CCS. But direct funding of research and development and demonstration will also be needed. Toman (2015) estimates that the current very low funding for research into alternative energy technologies may need to be scaled up by a factor of 20 to generate 'disruptive' rather than 'evolutionary innovations as would occur under a Global 'Apollo program'. The International Energy Agency (IEA) has estimated that $\$ 44$ trillion will be needed to maintain the objective of controlling the temperature rise at $+2^{\circ} \mathrm{C}$, on top of investments needed to meet growing energy demand. This will require public sector investment and cooperation that has not been addressed, at least directly, by the PA.

Energy transitions from the conventional high-energy emissions (HGE) coal power plants to low GHG emission (LGE) power plants are intrinsically slow. Understanding these delays is important because electricity generation accounts for about $40 \%$ of anthropogenic $\mathrm{CO} 2$ emissions. Using Life Cycle Analysis (LCA) estimates, Myhrvold and Caldeira (2012) contrast CO2 emissions under the deployment of LGE power plants (wind, solar PV, nuclear, solar thermal, CCS, and natural gas). They show that the LGE plants do result in lower operating emissions over their lifetimes but they will typically require greater up-front emissions. As an example, they estimate that a shift to natural gas power plants that emit half the GHGs as coal plants of the same capacity would require a century or longer to attain a $25 \%$ reduction in HGE warming. They also show (see their figure $1 \mathrm{C}$ ) that except for hydroelectric, electricity production under all LGE power plants result in increasing trends in $\mathrm{CO} 2$ emissions. They also estimate that unless the LCA estimates for CCS are on the low side of the estimated range, CCS cannot yield substantial temperature reductions this century. These estimates underscore the urgency of rapid deployment of the LGE electricity generation techniques.

\section{Damage Incidence and Burden sharing.}

In addressing the mitigation-adaptation-suffering nexus raised by Holdren, successful implementation of the PA still has to recognize that: (i) the poorest countries have been the most severely hit by climate shocks and are projected to be the most severely affected by climate

\footnotetext{
${ }^{16}$ Nuclear power remains dogged by cost overruns, public concerns and the long time line needed for the 'next generation reactors'. Carbon geoengineering which involves removing $\mathrm{CO}_{2}$ from the atmosphere is the only true backstop technology for addressing climate change. One problem with this technology is storage. However, unlike carbon capture at the power plant, there is more flexibility in locating direct $\mathrm{CO}_{2}$-removal technologies away from population centers. The bigger problem with this technology may be its high cost. The other approach is solar geoengineering. This technology reflects sunlight away from the earth, offsetting the effect of rising concentrations. However, this intervention isn't a backstop, as it would affect the climate differently than limits on concentrations. Most obviously, it would not limit ocean acidification. Ironically, a problem with this approach is cost. Solar geoengineering would likely be cheap, meaning that it may be in the interests of a single country to deploy. The primary problem with this technology is therefore governance.
} 
change in the future and the most vulnerable; (ii) financial commitments (and past and current transfers) for adaptation and mitigation to the poorest are orders of magnitude short of estimated needs; (iii) financial transfers from rich to poor countries for adaptation will be necessary for full participation by all as envisaged in the PA. With the exception of Sweden, raising carbon taxes has only barely started. Effecting the transfer faces the hurdle of meeting approval in the legislatures of the countries where the funds are collected. Cap-and-Trade schemes are an alternative that avoids the legislative hurdle. Shutting down coal progressively is another option to transfer resources, but it comes at large efficiency costs since coal is the least efficient source of energy production. ${ }^{17}$

\subsection{Damage Incidence, past and projected}

Figure 3a plots $\mathrm{CO} 2$ emissions of GHGs from fossil fuels against population shares by regions for 2015. Total emissions are indicated in the bubble (the size of each bubble is proportional to that region's share in total emissions) along with per capita emissions. Regions above (below) the $45^{\circ}$ line have above (below) average per capita emission intensities. While net per capita emissions of all GHGs (including methane and deforestation) are to converge to zero to arrest global warming, convergence in per capita emissions is a plausible benchmark of the required intensity of adjustment across. China is the heaviest emitter followed by the US while Sub-Saharan Africa (SSA) contributes a negligible amount. In fact, Chancel and Piketty (2015, figure 7), estimate that per capita CO2 emissions of the $4 \%$ poorest people in the world (mostly in SSA) decreased over the period 1998-2013. At the same time, most low-cost mitigation potential is also in low-income countries (see the MAC estimates for India in table 1).

\footnotetext{
${ }^{17}$ Noting that coal is an inefficient source of energy extracted by the few and consumed by the many, Collier (2015) proposes on equity grounds shutting down coal progressively starting in high-income countries then moving down the ladder towards middle and low-income countries. This is a very inefficient solution that would still require cooperation.
} 
Figure 3: Past (3a) and Projected (3b) $\mathrm{CO} 2$ emissions by region

Figure 3a: Past $\mathrm{CO}_{2}$ emissions by regions

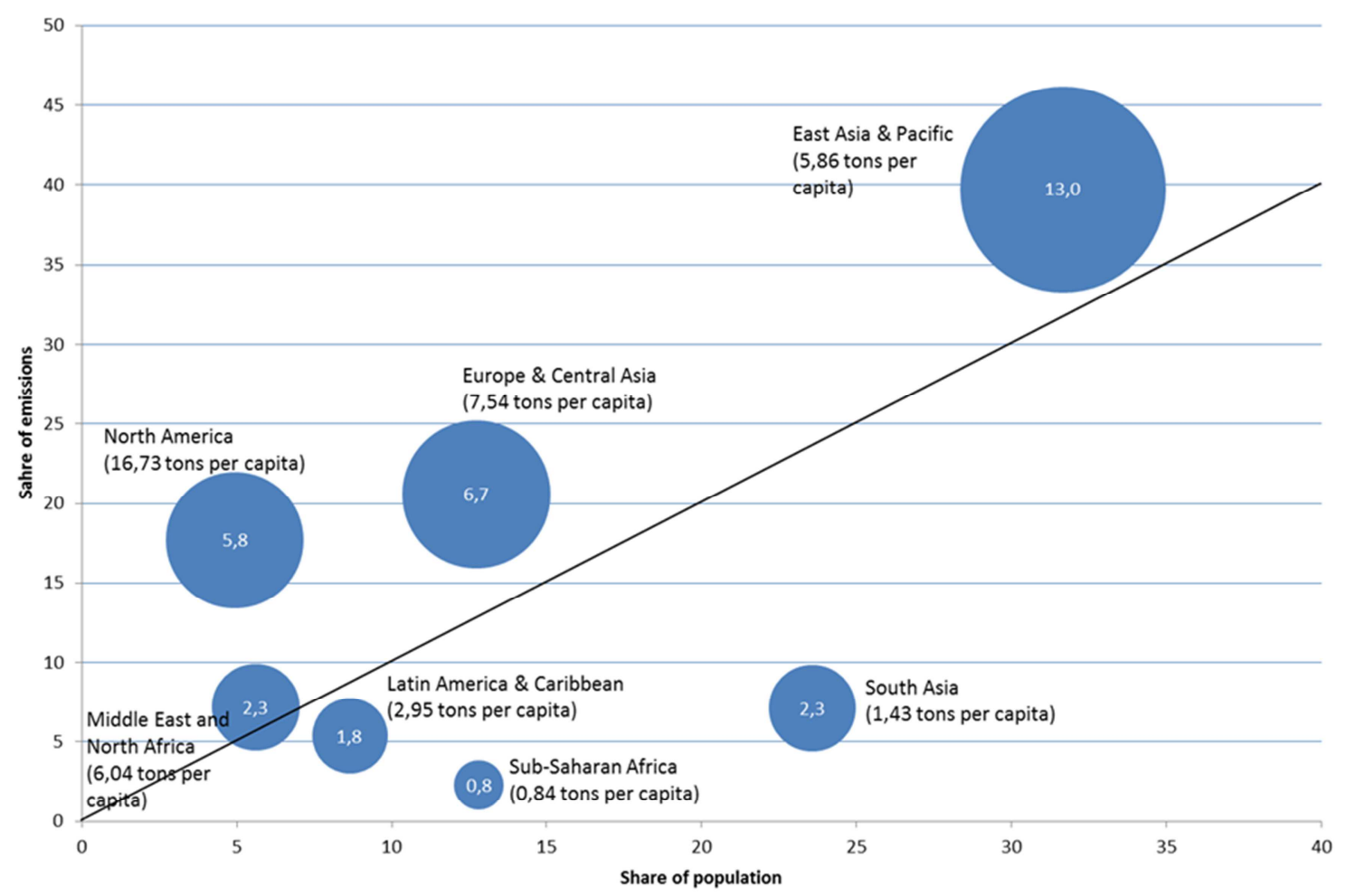

Figure 3b Projected damages by regions in 2050

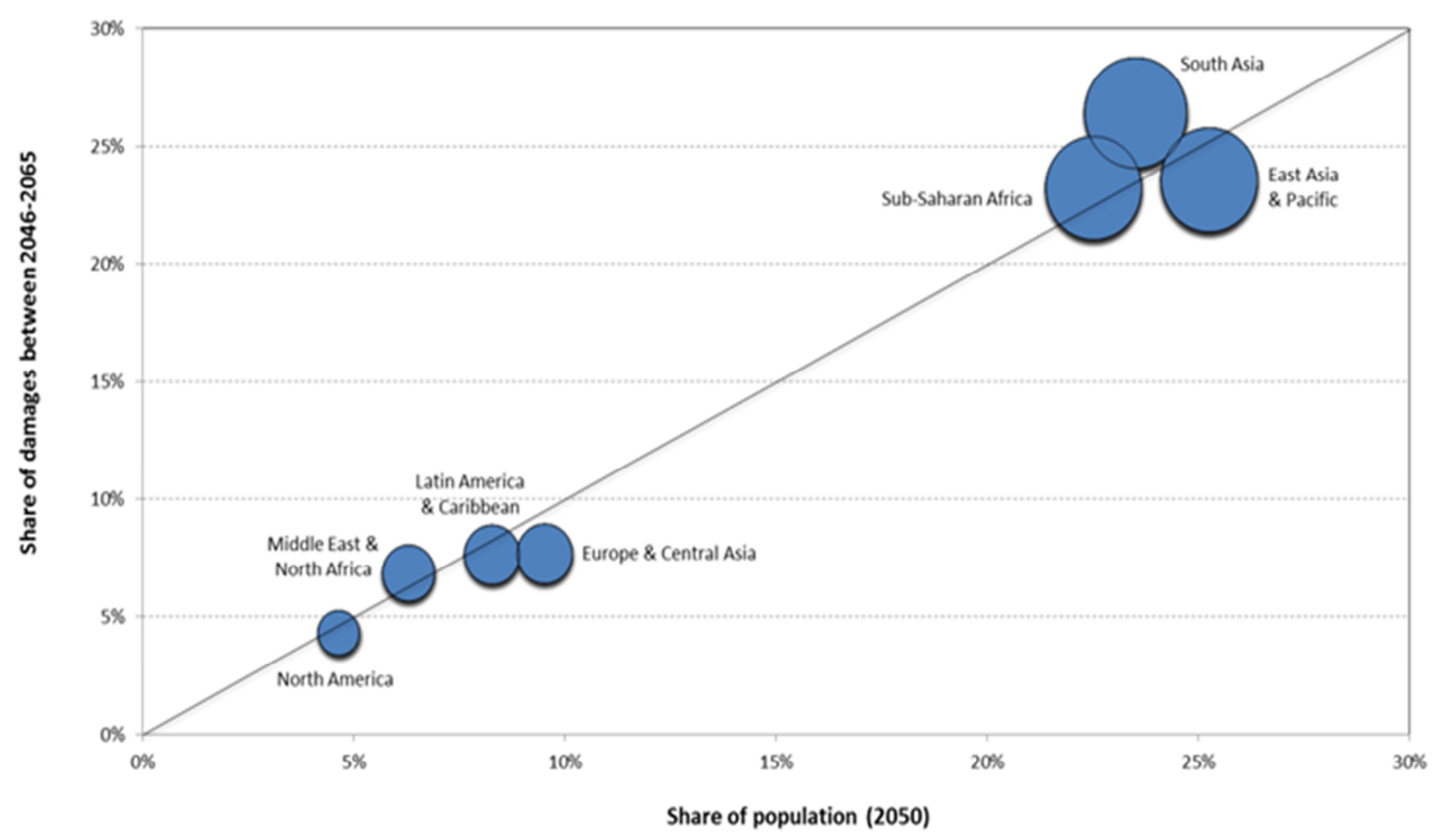

Source: Corneille and Melo (2016). 
If Africa contributes the least to climate change, it is also the region that is estimated to lose the most ( $2-4 \%$ of GDP) in the coming 10 to 50 years $(50-80 \%$ of land, livestock and population are already in drylands with the poor most exposed to climate shocks). Of the 48 Least Developed countries (LDCs) that are most vulnerable to natural and economic shocks, 34 are in Africa. Moreover, it is the poorest segments of their population that are at risk because they settle in the riskiest areas that are most affordable to them. The poor are least resilient, receive smaller shares of social protection and, knowing ex-ante that they are uninsured against natural hazards including the attendant deterioration in health (low and lower-middle income countries account for one third of all disaster but account for more than $80 \%$ of all deaths), they engage in low-risk, lowreturn activities that perpetuate poverty.

Figure $3(b)$ plots the share of estimated damages from extreme temperatures (i.e. the predicted number of days per year outside the $90^{\text {th }}$. percentile of the temperature distribution) against estimated population shares in 2050 (the size of the bubbles this time indicating regional population shares), the $45^{\circ}$ degree line again indicating whether regions are predicted to get damages greater (i.e. above the line) or lesser (below the line) than population shares. Climate models predict that temperature increases will be greater at high than at low latitudes $\left(8^{\circ} \mathrm{C}\right.$. vs. $4^{\circ}$ C) but that the high warming in high latitudes occurs against a backdrop of high variability while the ratio of warming to internal variability is low in the low latitude $\left(\cong 25^{\circ} \mathrm{N}-25^{\circ} \mathrm{S}\right)$ regions where most of SSA is located. And it is low variability in the high-temperature low-latitude regions that will cause the largest damages. Hence, figure $3 \mathrm{~b}$ predicts higher damages from average temperature increases in the low latitude regions of SSA and South Asia (SA). Three remarks are in order. First, if the population growth projections are approximately accurate, the redistribution of population shares across regions (in the absence of migration) will be strong before the end of the century. Second, even if income per capita convergence continues, SSA and SA will be the regions that will bear the brunt of climate change. Third, in the absence of successful adaptation, migratory pressures towards regions with low population densities will be great.

\subsection{Mobilising Climate finance.}

Raising the funds and transferring them to the low-income countries is the greatest challenge facing implementation of the PA. Not only must the $\$ 100$ billion pledged for the Green Climate Fund be raised, but it must also include funding for the recently agreed SDGs, estimated at $\$ 5-\$ 7$ trillion annually. The World Bank (2010) estimates the needs of the developing world at $\$ 140-\$ 175$ billion a year by 2030 for mitigation actions and another $\$ 75-\$ 100$ billion for adaptation. These estimates, necessary to address the fairness issue are two to three times the $\$ 100$ billion per year commitment agreed at Copenhagen in 2009. Finance will have to be raised from all sources, public and private, local and international. For official financial flows, criteria will be needed for disbursements (countries or sectors, mitigation or adaptation). 
So far, the 'alternative sources' of finance identified in 2009 (carbon markets and prices, taxes on transport and international financial transactions and the green bond market) have been disappointing. According to the Climate Policy Initiative, $\$ 391$ billion were invested in climate finance in 2014, less than the estimated $\$ 490$ billion fuel subsidies for consumption. Improvements in the regulatory environment are needed. An exemplary case is France that makes mandatory climate disclosure requirements for listed companies and financial institutions (article 173 of the Energy Transition for Green Growth). Other improvements will also be needed for climate finance to extend beyond national borders (currently three quarters of climate finance is spent in the originating country/region). New tools are also needed to kick-start this transition. One option, favored by Hourcade (2015) would be the creation of government-backed 'climate remediation assets' that would provide the currently lacking guarantee for private investments. Carbon prices alone cannot do the job. In the absence of a benevolent lender, high upfront costs of low-carbon projects under uncertainty about the cost of equipment and the duration of the maturation phase of the projects mean that investments which could be profitable are frozen. The creation of 'climate remediation assets' based on a governments' public guarantee, along with carbon pricing, would remove this barrier to investing in low-carbon activities.

\subsection{Burden Sharing}

Linkage-unilateral or bilateral-recognition of allowances in a CAT across jurisdictions is a way to transfer funds that bypasses the legislative process. Linkage reduces carbon price differentials across countries/regions and hence incentives to lobby for exceptions to emission targets agreed by the countries under the PA. This reduces leakage. With linkage, firms under a CAT exchange emission allowances (or Emission Tax Payment Credits (ETPCs)) that could be sold by firms under a carbon tax to firms under a CAT. Linkage improves cost-effectiveness but it requires capacity and motivation to track emissions and emission allowances (Stavins, 2015). Supplementary conditions like "sustainable development actions" under the Clean Development Mechanism (CDM) of the KP inhibit effective linkage. In the end, the CDM has only been used by a few developing countries resulting in financial transfers to only a few countries (mostly to China), and the intended technological transfer under the CDM has been limited (Schmid, 2012).

The EU European Trading System (ETS) is a good example of how one might expect linkage to operate. Babonneau et al. (2016) model the EU "Energy-Climate" directive calling for a reduction in GHG emissions of $80 \%$ in 2050 relative to 1990 levels among the 28 Member States. This amounts to considering how $99 \mathrm{Gt} / \mathrm{CO} 2$ would be allocated to the Member States and how they might exchange them. Babonneau et al. consider allocation rules for the distribution of allowances (past emissions, ability to pay, egalitarian and a 'fair' rule minimizing the largest welfare losses across members) similar to those in figure 4 across countries. Member States then have the choice on how to allocate their supply of allowances each period to a perfectly competitive market for emissions allowances. 
The results for a selection of countries reported in table 2 show very large differences in the welfare effects over the period except under the model-generated fair allocation rule (Rawlsian rule of minimizing the largest welfare loss among countries) in which case the welfare losses are quasi identical by construction. The results show large differences in welfare effects for new EU members. Welfare effects for Estonia range from $-20.0 \%$ to $7.9 \%$ while for Germany the range is $1.9 \%$ to $-2.2 \%$. The ability-to-pay rule favors new EU members (Bulgaria, Estonia, and Poland) while the egalitarian rule favors countries with low per capita emission levels (Sweden and France) and the sovereignty rule those with low $\mathrm{CO} 2$ abatement costs (France, Sweden). Viewing the EU-ETS as representative of a CAT involving high and low-income countries, the transfers and associated financial flows would be huge, giving rise to gaming that would make those under the CDM pale in comparison. ${ }^{18}$

Table 2: Burden sharing under a CAT: the EU Climate Directive: 2010-2050

\begin{tabular}{|c|c|c|c|c|c|c|c|}
\hline \multirow[b]{2}{*}{ Column } & \multirow[b]{2}{*}{$\begin{array}{c}\text { Cumulative } \\
\text { Household } \\
\text { Consumption in } \\
\text { BAU }\end{array}$} & \multirow[b]{2}{*}{$\mathrm{CO} 2 / \mathrm{pc}$} & \multirow[b]{2}{*}{$\begin{array}{c}\mathrm{CO} 2 \\
\text { share }^{d}\end{array}$} & \multicolumn{4}{|c|}{ Allocation Rule for carbon allowances ${ }^{a}$} \\
\hline & & & & Sovereignty & Ability to pay & Egalitarian & Fair \\
\hline & & & & \multicolumn{4}{|c|}{ Welfare loss (gain) $^{d}$} \\
\hline $1^{b}$ & & 2 & 3 & 4 & 5 & 6 & 7 \\
\hline BGR(4379) & 745770 & 6.0 & 1.2 & -10.5 & -26.2 & -20.0 & 1.2 \\
\hline POL(9933) & 7905470 & 8.2 & 8.5 & -5.6 & -16.9 & -2.9 & 1.2 \\
\hline EST (10450) & 348130 & 14.9 & 0.5 & $-5-7$ & -20.0 & 7.9 & 1.2 \\
\hline FRA(34029) & 43609940 & 5.5 & 9.6 & 2.6 & 4.1 & 0.8 & 1.2 \\
\hline SWE(42822) & 6623250 & 5.5 & 1.4 & 2.7 & 6.9 & 0.9 & 1.3 \\
\hline GER(36193) & 52238130 & 9.5 & 20.8 & -1.9 & 2.2 & 0.2 & 1.3 \\
\hline \multicolumn{8}{|l|}{ Total transfers ${ }^{c}$} \\
\hline $2030(382)$ & & & & 71700 & 174600 & 115000 & 46600 \\
\hline $2050(1103)$ & & & & 509700 & 586000 & 406000 & 157000 \\
\hline
\end{tabular}

\section{Notes :}

a/ Allocation of carbon allowance for $99 \mathrm{Gt}$ emissions over 2010-40 period relative to BAU projected emissions of $174 \mathrm{Gt}$. See text for definition of allocation rules.

b/ Per capita GDP in 2005 dollars in parenthesis.

c/ Total financial transfers (in Million 2007\$) across member states estimated from emission trading in that year at prices in parenthesis.

d/ Percent

Source: Babonneau et al. (2016) tables 1 and 2. Welfare measured as the discounted (at 5\%) household consumption (a negative number is a welfare gain). In the absence of the Energy climate directive, the welfare gain would be the Cumulative Household Consumption in BAU.

Turn now to estimates of burden sharing of mitigation efforts for a broader range of countries when there is no market for allowances. Figure 4 shows a range of mitigation efforts that might be expected under burden-sharing approaches based on efforts at the country level. These emission reductions are for 2030 under the assumption that countries are moving along a linear reduction path to reach the $+2^{\circ} \mathrm{C}$ target with a $2 / 3$ probability of success by the end of the century. Under an

\footnotetext{
${ }^{18}$ See the large transfers of Annex 1 countries for low-cost abatement projects reported in Wara and Victor (2008).
} 
egalitarian 'right to emit' approach where each country gets a share determined by its projected population, the US has already overshot its entire budget, China has to reduce its emissions by $35 \%$ from 2010 levels (China has pledged to reach peak emissions by 2025) and India can increase its emissions by $154 \%$. Under a 'responsibility' approach that takes into account historical contributions by subtracting cumulated emissions over the period 1990-2020 from the budget, China and India can still increase their emissions, but this is no longer the case for China under a 'capacity to pay' based on per capita income. A 'least cost' allotment would tilt slightly mitigation towards developing countries where marginal abatement costs are estimated to be lower. India appears to be the only country that could always escape having to reduce emissions below 2010 levels.

Figure 4: Post 2030 emission targets under alternative 'burden sharing' approaches

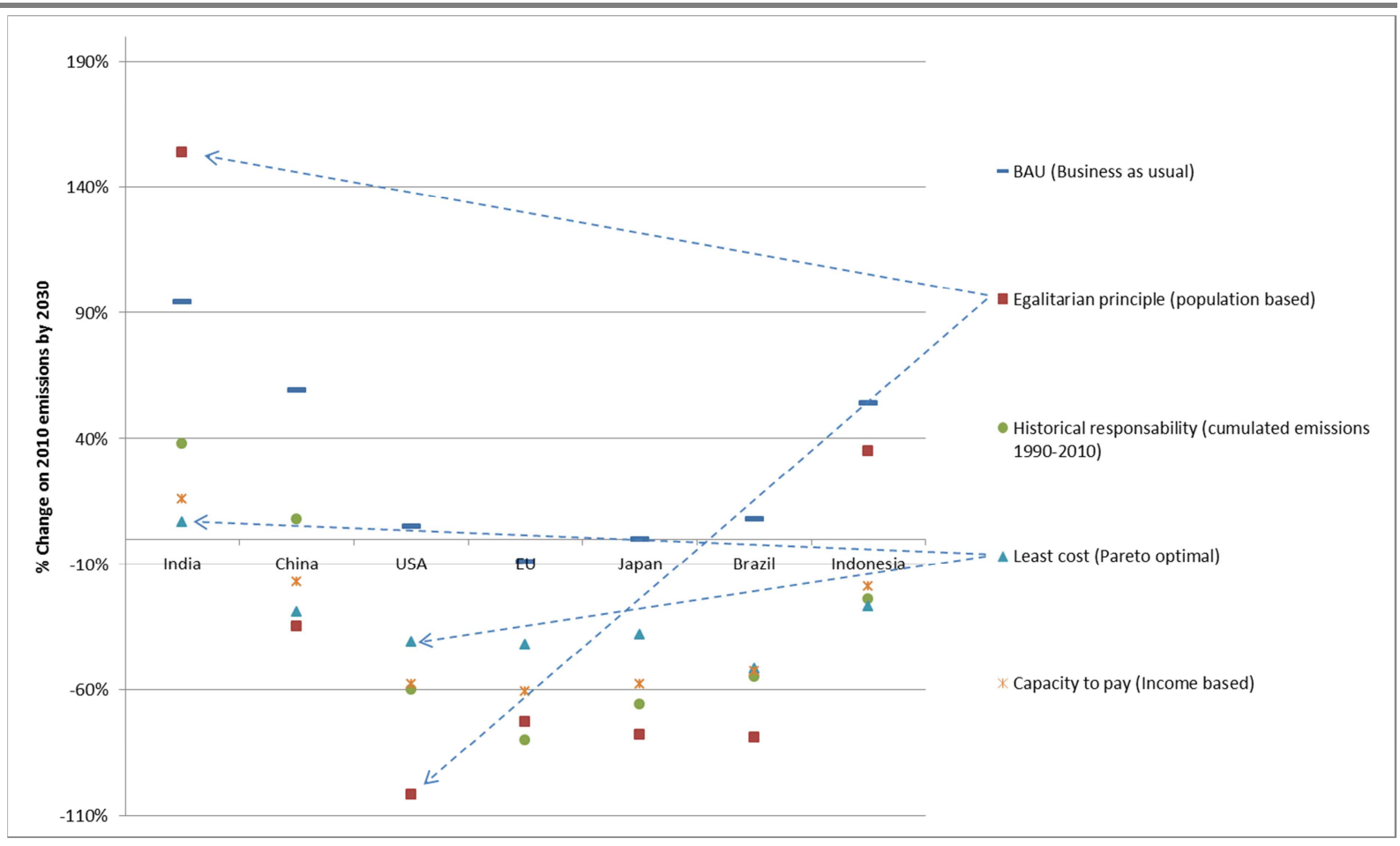

Source: Averchhenkova et al (2014) Source: Averchenkova, Stern and Zenghelis (2014, table 3) ${ }^{19}$ Notes: 2010 base year; $41 \mathrm{Gt}$ CO2e global emission target in 2030

Turn next to contributions for adaptation in developing countries. These are typically discussed in terms of country-level contributions based on averages of $\mathrm{CO} 2$ emissions for a group of highincome countries (preferably using consumption-based estimates as in the estimates in table 2 , column 4). Relying on the UNFCCC "Common but Differentiated Responsibilities (CBDR)" principle over the period 1820-2010, Western Europe, North America, Japan and Australia should contribute for $50 \%$ and China $12 \%$ (their respective shares of cumulated emissions over the period 1820 -

\footnotetext{
${ }^{19}$ The model does not include the dynamics of lock-in and path-dependence for infrastructure, knowledge spillover, network effects, and institutions and behaviors. Neither are included the effects of emission reductions on the value of the stock of stranded assets and attendant terms-of-trade effects.
} 
2010). A distributive justice approach (or 'respective capabilities') approach would use a breakdown of contributions according to GDP or per capita income as followed in the mitigation efforts reported in figure 4.

A third approach is to recognize that the spirit of the PA calls for universal participation. This would require sharing strategies that take into account within-country inequalities in emissions. Table 2 from Chancel and Piketty (2016) shows three scenarios for raising $\$ 150$ billion yearly $(0.2 \%$ of world GDP) for a climate adaptation fund based on a two-bracket global progressive carbon tax with a $0 \%$ carbon tax on emissions below a certain threshold. ${ }^{20}$ Column 1 shows the shares corresponding to a flat carbon tax with a zero threshold. Column 2 sets the contribution threshold to the top $10 \%$ individual emitters and column 3 reports contributions from a tax on air tickets. Under all scenarios close to $60 \%$ of the funds would be raised from the combined contributions of the US, the EU and China. Clearly the new geography of global emissions calls for climate action by all countries which, in the case of China, puts it at odds with its leadership role in the Like-Minded Developing Country (LMDC) group that seeks to safeguard their common interests (e.g. CBDRs).

\section{Table 3 Contributions to a Climate Adaptation Fund}

\begin{tabular}{|c|c|c|c|c|}
\hline Regions & $\begin{array}{l}\text { Effort sharing } \\
\text { according to all } \\
\text { emissions (flat } \\
\text { carbon tax) (\%) } \\
\text { (1) }\end{array}$ & $\begin{array}{l}\text { Effort sharing among } \\
\text { top } 10 \% \text { emitters } \\
\text { (above } 2,3 \times \text { world } \\
\text { average) (\%) } \\
(2)\end{array}$ & $\begin{array}{l}\text { Effort sharing } \\
\text { according to a } \\
\text { global tax on air } \\
\text { tickets (\%) } \\
\text { (3) }\end{array}$ & $\mathrm{tCO}_{2} \mathrm{e}$ per person per year \\
\hline North America & 21,2 & 46,2 & 29,1 & 22,5 (N. Americans) \\
\hline EU & 16,4 & 15,6 & 21,9 & 13,1 (West. Europeans) \\
\hline China & 21,5 & 11,6 & 13,6 & 6 (Chinese) \\
\hline Russia/C. Asia & 6 & 6,3 & 2,8 & \\
\hline Other Rich & 4,6 & 4,5 & 3,8 & \\
\hline Middle East/N.A. & 5,8 & 5,5 & 5,7 & 7,4 (Middle East) \\
\hline Latin America & 5,9 & 4,1 & 7 & 4,4 (Latino Americans) \\
\hline India & 7,2 & 0,7 & 2,9 & 2,2 (S. Asians) \\
\hline Other Asia & 8,3 & 4,1 & 12,1 & \\
\hline S.S. Africa & 3,1 & 1,5 & 1,1 & 1,9 (Africans) \\
\hline World & 100 & 100 & 100 & 6,2 (World avg.) \\
\hline
\end{tabular}

Source: Chancel and Piketty (2015, table E.4. and 3)

Notes: a/ tax rate on all flights: $€ 180$ per business class ticket; $€ 20$ per economy ticket

\footnotetext{
${ }^{20}$ The income elasticity of $\mathrm{CO} 2$ emissions based on household consumption surveys detailing expenditures by income level with expenditures broken down into transport, and household energy requirements (cooling, heating, electrifying) is 0.9 so that the growth incidence emission curve for $\mathrm{CO} 2$ is quasi-identical to that for the income of individuals so the contribution estimates are close to those one would obtain from applying an income tax.
} 


\subsection{Forest Conservation.}

A decade ago, high hopes were placed on reductions in rates of deforestation: (i) low cost (at $\$ 5$ per tCO2, reducing deforestation rates by half would only cost $\$ 9-\$ 10$ billion per year) and : (ii) high hopes for results-based payments mechanisms since, thanks to satellite information, compensating for a reduction in rates of deforestation largely fulfills MRV conditions. Ten years on, vested interests still hold the power to block the policy reforms that are needed to shift the balance of interests towards forest conservation. A flawed process for allocating concessions and land rights reflecting a lack of ownership at the national level combined with REDD+ processes run at the international level has resulted in few results on the ground. Yet, as has been repeatedly said (e.g. recently in the New Climate Economy Report "Better Growth, Better Climate") forest conservation will have to play a central role in the contribution of REDD+ countries to the global effort at limiting climate change.

Angelsen (2015) singles out improvements leading to national commitment policies. These include pressure from consumers on corporations, and 'entrepreneurial authority' coming from private actors defining new standards. There are the steps necessary to extend REDD+ activities beyond the initial vision of a vehicle of international transfers. Combined with assessment and review, REDD+ would then become an integral part of countries' national contributions to the global efforts at curbing climate change. For forest conservation to generate the hoped-for contribution to arrest climate change, Angelsen concludes that REDD+ countries will have to take the driver's seat which they may have difficulty doing because of weak governance or be reluctant to do until financial resources from developed countries are truly forthcoming.

\section{Conclusions}

By including all nations, the PA agreement, now a Treaty, has overcome the 'deep but shallow' outcome of the KP, but the 'bottom-up' pledges fall short of meeting the targets announced in Paris and even more so those of Article 2 of the UNFCC engagement of putting the planet on a sustainable development path. Ramping up mitigation later to reach the required net zero $\mathrm{CO} 2$ emissions will call for sharper emission cuts (perhaps 6.3\% a year if starting in 2020 rather than 4.4\% a year if cuts had started in 2015). In the bottom-up approach, accelerating mitigation effort will also require trust to come from increased transparency through a 'top-down' MRV process, the details of which are yet to be worked out and for which early model-based estimates show large discrepancies.

Annual financial transfers to low-income countries estimated at three times or more the pledges made in 2009, will be the glue to keep the process on track for a number of foreseeable reasons that include high population and urbanization growth rates that will be carbon-intensive. If a widespread tax on carbon will be an essential ingredient of measures to carry out, the experience of transferring resources to low-income countries through reductions in deforestation rates that are close to satisfying MRV conditions suggest that it will prove difficult. Transfers that avoid the 
legislative process like linkage across carbon markets in different countries and other 'clever' but less-efficient measures will have to be considered.

Because the intensity of potential damage is dynamic (i.e. depends on the stock of $\mathrm{CO} 2$ emissions) the probability of damage is revised upwards through time. An example is the recent upward revision about expected sea-level rise by the end of the century. Even with extraordinary success at cutting emissions, the most recent predictions from climatologists are that the West Antarctica ice sheet cannot be saved locking in a sea-level rise of about 5 meters. Catastrophe could be in the offing if temperatures rise beyond $+3^{\circ} \mathrm{C}$ since pre-industrial times. And since we are already reaching uncharted temperature ranges, we have little evidence to make predictions about temperature increases (and also about the sensitivity of temperature to the stock of $\mathrm{CO} 2$ emissions) and about the resulting damages. Finally, taking into account the estimated delays to obtain a reduction in temperature increase from energy obtained under other sources than coal (it is estimated to attain a $25 \%$ reduction in warming from a shift to natural gas power plants of the same capacity might require a century) it is hard not to conclude that pledges so far reflect reaction rather than caution.

Incentives will also be needed for parties actually to do more, among which incentives to raise the very low research funding for clean energies by perhaps a factor of 20 to generate 'disruptive' rather than 'evolutionary' innovations are high on the priority list. These incentives may not come only from within the United Nations Framework Convention on Climate Change (UNFCCC) process. They may also come from other sources, such as the recent effort underway now to amend the Montreal Protocol to limit hydrofluorocarbons (HFCs) or the timid agreement to increase fuel efficiency of airplanes or maritime fuel. More optimistically, a number of initiatives by the nongovernment sector described in the paper appear promising. 


\section{References}

- Aldy, Joseph, (2014) "The Crucial Role of Policy Surveillance in International Climate Policy", Climatic Change, 126(3), 279-2

- Aldy, Joseph, William Pizer et al. (2016) "Economic Tools to Promote Transparency and Comparability in the Paris Agreement", Nature and Climate change,

- Averchenkova, Alina, Nicholas Stern and Dimitri Zenghelis (2014) "Taming the beasts of 'burden-sharing': an analysis of equitable mitigation actions and approaches to 2030 mitigation pledges", Grantham Resarch Institute on Climate Change and the Environment

- Babonneau, Frédéric, Alain Haurie, and Marc Vielle (2016) « Assessment of balanced burden- Sharing in the $2050 \mathrm{EU}$ climate/energy roadmap: a metamodeling approach", Climatic Change, 2016, 134:505-19

- Barrett, Scott, Carlo Carraro and Jaime de Melo eds. [BCM] (2015) Towards a Workable and Effective Climate Regime, VoxEU.org eBook, CEPR and FERDI

- Bigio, Anthony (2015) "Towards Resilient and Low-carbon Cities" chp. 30 in (BCM)

- Bodansky, Daniel (2016) "The Legal Character of the Paris Agreement", Review of European, Comparative, and International Environmental Law, Forthcoming

- Burke, M, J. Dykema et al. (2015) "Incorporating climate Uncertainty into Estimates of Climate Change Impacts", The Review of Economics and Statistics, 97(2), 461-71.
- Calel, R., D.A. Stainforth, and S. Dietz (2015) "Tall Tales and Fat tails: the science and economics of extreme warming", Climactic Change, 132: 127-141

- Chancel, Lucas and Thomas Piketty (2015) "Carbon and Inequality: From Kyoto to Paris: Trends in the Global Inequality of Carbon Emissions (1998-2013) and Prospects for an Equitable Carbon Fund", PSE

- Coninck, Helen de, and Shikha Bhasin (2015) “Meaningful Technology Development and Transfer: A Necessary condition for a Viable Climate Regime", chp. 31 in BCM

- Corneille, Adrien, and Jaime de Melo (2016) “Les défis de l'Afrique Subsaharienne face au changement climatique» Policy brief \#165, FERDI

- De Conto, Robert and David Pollard (2016) "Contribution of Antarctica to Past and Future sea-level rise", Nature, 531, 591-7

- Dell, Melissa, Benjamin Jones, and Benjamin Olkien (2012a) «Temperature Shocks and Economic Growth: Evidence from the Last Half Century", American Economic Journal: Macroeconomics, 4:3, 66-95.

- Dietz, Simon and Nicholas Stern (2015) «Endogenous Growth, Convexity of Damage and Climate Risk: How Nordhaus' Framework Supports Deep Cuts in Carbon Emissions", Economic Journal, 574-617

- Gollier, Christian, Bruno Jullien \& Nicolas Treich (2000). "Scientific Progress and Irreversibility: An Economic Interpretation of the 'Precautionary Principle'". Journal of Public Economics. 75 (2): 229-253 
- Green, Jessica, (2014) Rethinking Private Authority: Agents and Entrepreneurs in Global Environmental Governance, Princeton, Princeton University Press

- International Energy Agency (2015), World Energy Outlook Special Report: Executive Summary, Paris: IEA.

- Henderson, J. Vernon, Adam Storeygard, Uwe Deichman (2017) "Has Climate Change Driven Urbanization in Africa?" Journal of Development Economics, 124, 60-82

- Mavroidis, Petros and Jaime de Melo (2015) «Climate Change Policies and the WTO: Greening the GATT, revisited", chp. 16 in BCM

- Massetti, Emmanuelle, (2015) "The Macroeconomics of Climate Policy: Investments and Financial Flows" chp. 32 in $\mathrm{BCM}$

- Mathys, N. and J. de Melo (2011) "Political Economy Aspects of Climate Change Mitigation Efforts", The World Economy , 34(11), 1938-54

- Myhrvold, N.P. and K. Caldeira (2012) "Greenhouse Gases, climate change and the transition from Coal to low-carbon electricity", Environment Research Letters, 7(1),

- Mo, Kevin (2016) "Financing Energy Efficiency Buildings in Chinese Cities", Paulson Institute,

- Nordhaus, William, (2008) A Question of Balance: Weighing the Options on Global Warming Policies, New Haven, CT, Yale University Press.

- Nordhaus, W. (2015), “Climate Clubs: Overcoming Free Riding in International Climate Policy," American Economic Review 105(4): 1339-1370.
- Parry, lan, Chandra Veung and Dirk Heine (2014) " How Much Carbon Pricing is in Countries' Own Interests? The Critical Role of Co-Benefits", IMF WP/14/174

- Pindyck, Robert S. (2013) "Climate Change Policy: What do Models Tell us?", Journal of Economic Literature, 51(3), 860-72

- Schelling, Thomas (2007) "Climate Change: The Uncertainties, the certainties, and what they Imply for Action", Economists' voice,

- Schmalensee, R. (1998) “Greenhouse policy architecture and institutions", Economics and Policy Issues in Climate Change, p137-158.

- Schmid, G. (2012) "Technology Transfer under the CDM: the role of country characteristics", Climate Policy, vol 12(6), $722-40$

- Stavins, Robert N, (2015) “Linkage of regional, national and sub-national policies in a future international climate agreement", chp. 20 in BCM

- Stern, Nicholas (2013) "The Structure of Economic Modeling and the Potential Impacts of Climate Change: Grafting Gross Underestimation of Risk onto Already Narrow Science Models", Journal of Economic Literature, 51(3), 838-59

- Sterner, Thomas and Gunnar Kohlin (2015) “Pricing Carbon", chp. 18 BCM

- Stocker, Thomas (2013) "The Closing Door of climate Targets", Science, 339,280-2

- Stocker, Thomas (2015) "Implications of Climate Science for Negotiators", chp. 2 in BCM

- TCFD (2016) "Phase I Report of the Task Force on Climate-related Financial Disclosures", Financial Stability Board 
- Toman, Michael (2015) "International Cooperation in Advancing Energy Technologies for Deep Decarbonisation", chp. 22 in BCM

- Keohane, Robert and David Victor (2015) "After the Failure of Top-down mandates: The Role of Experimental Governance in Climate Policy", chp. 14 in BCM
- Wagner, Gernot and Richard Zeckhauser (2016) "Confronting Deep and Persistent Climate Uncertainty", Kennedy School, DP \#16-14

- Wara, M. and D. Victor (2008) "Trading in Fake carbon credits: Problems with the Clean Development Mechanism", Friends of the Earth

- World Bank (2009) World Development Report: Reshaping Economic Geography, Washington, D.C. 
"Sur quoi la fondera-t-il l'économie du monde qu'il veut gouverner? Sera-ce sur le caprice de chaque particulier? Quelle confusion! Sera-ce sur la justice? Il l'ignore."

Pascal

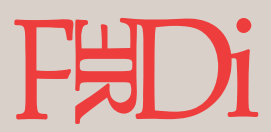

Created in 2003, the Fondation pour les études et recherches sur le développement international aims to promote a fuller understanding of international economic development and the factors that influence it.

\section{$\hookrightarrow$ Contact}

www.ferdi.fr

contact@ferdi.fr

+33 (o)4 73177530 